\title{
Topical issues of legal regulation of labor relations in the educational sector in the context of the pandemic
}

\author{
Tatyana Moskaleva, ${ }^{1, *}$ \\ ${ }^{1}$ Don State Technical University, 344003, 1 Gagarin Square, Rostov-on-Don, Russia
}

\begin{abstract}
The purpose of this study is to identify the dependence of the impact of the pandemic on changes in the regulation of labor relations in the educational sector. At present, serious changes have taken place not only in our country, but also in the world community as a whole. This is primarily due to the spread of the coronavirus pandemic, which has affected all areas of society. The educational process is no exception. The coronavirus pandemic has triggered a transformation of the educational process, at all levels. In the past year, this term has become one of the most widely used terms to describe the current state of the world that affects areas of society. The consequences of the pandemic are felt everywhere, it is a real phenomenon. Today, we can talk about the impact of the pandemic on economic, political, cultural, and international relations, which extends beyond any traditional borders. Changes in these areas are common to all states. Understanding the nature and direction of this phenomenon can help to form new principles of interaction between individual segments of society, as well as between community and the state.
\end{abstract}

\section{Introduction}

Let's look at the impact of the pandemic on education. The pandemic has been the subject of researches of many scientists: historians, philosophers, sociologists, economists, lawyers, ecologists who study the impact of the pandemic on society from various angles. Many articles have been written on this topic, and there are discussions and disputes about the impact of the pandemic on the educational process (O. V. Shmurygina, 2020, A. Kondakov 2020) [1]. The authors agree that the coronavirus pandemic has started the process of digital transformation of the educational process. However, there is still very little research on the impact of the pandemic on the regulation of labor relations of educational workers.

Methodological analysis of risks from the impact of the pandemic should be carried out in the context of integration of the economic, political and legal space. From this point of view, the risk of a pandemic is the possibility of undesirable economic events that need to be taken into account in the public life of a society, that is, the economic risk reflects the

\footnotetext{
*Corresponding author: spu-53.6@donstu.ru
} 
possibility of the destructive nature of undesirable economic events. The most undesirable economic situation of a destructive nature is, first of all, the fall in oil prices, the income from the sale of which on the world market is the main source of refilling the budget of our country. In any case, this will affect both micro and macroeconomic processes, partially destroying the established principles of interaction in all areas of society, including the educational sector.

\section{Materials and methods}

The study analyzes the following issues:

- negative impact of the pandemic on the labor market in education

- decline in the quality of the educational process in the context of the education system's failure to fully digitalize the educational process.

The subject of the study is the analysis of ways and tools for the formation of new principles for regulating labor relations in the context of the pandemic.

The complex nature of the conducted study resulted in the use of various methods in analyzing the impact of the pandemic on changes in the legal regulation of labor relations in the educational sector. The main method is the system analysis of the studied problematic issues. Other methods of studying and analyzing the impact of the pandemic on the formation of new principles of interaction between employees and employers were also used, including: general scientific-didactive and formal-logical methods of cognition, analysis, synthesizing.

\section{Results}

The legal regulation of labor relations in the field of education is reflected in legal acts of various legal force, since the right to education itself is consolidated as in the Declaration of human and civil rights and freedoms of November 22, 1991 in article 27: "Everyone has the right for education. Education is guaranteed to be accessible to all and free of charge within the limits of the state educational standard. Basic education is compulsory"[2]. These principles are also set out in the Constitution of the Russian Federation, which proclaims that "everyone has the right for education, in addition, the accessibility and free of charge of pre-school, basic general and secondary vocational education in state or municipal educational institutions and enterprises are guaranteed"[3].

The Labor Code of the Russian Federation, as one of the main sources of labor law, in Chapter 52 sets out a number of features of labor regulation for employees of the educational sector, namely:

-educational qualification, only if the employee is allowed to work as a teacher;

-peculiarities of working time and rest time;

-requirement for mandatory periodic professional development and certification;

-mandatory medical examinations;

-features of the structure of remuneration;

-features of concluding and terminating an employment contract with teachers;

-allowances and social support measures established by the state for teaching staff [4].

The educational qualification for a teacher is also established in clause 1 of the article 46 of the Federal law "On education in the Russian Federation" dated December 29, 2012 No. 273-FZ (hereinafter-the Federal law "on education"), where it is stated that "the right to engage in teaching activities is granted to persons who have a secondary professional or higher education and meet the qualification requirements specified in the qualification reference books and (or) professional standards"[5]. 
Thus, the law establishes the requirements for employment, guarantees and compensation for employees of educational institutions.

However, the pandemic has had a significant impact on the entire educational process. So, due to the threat of the spread of coronavirus, educational institutions have urgently introduced distance learning. For obvious reasons, not only students, teachers, and the entire education system were not ready to change the format of the educational process from full-time to remote in an emergency mode. And there are several reasons for this: significant changes in the working conditions of teachers, the lack of readiness and ability of teachers to accept the new realities of the time, the lack of conditions and programs for distance learning, and of course the lack of a regulatory basis for such changes.

To define the concept of distance education, let us turn to thefollowing definition: "Distance education can be defined as education carried out through Internet technologies, in which the student is removed from the teacher and learning laboratories. Education, which is carried out through Internet technologies, in which the student is removed from the teacher and educational laboratories, we will call distance "[6]. This definition most fully reflects the essential features of distance education.

Analyzing distance learning we can identify the following problem areas of legal regulation of labor relations in the context of the pandemic:

-lack of local regulations that would regulate the transition to distance learning;

- poorly organized realization of distance learning;

-lack of an effective system for remunerating teachers for the development and implementation of online courses;

- not providing timely assistance to teachers to improve their skills in the field of online learning;

-teachers are not ready to implement the online mode: - informationand technology gap for the implementation of distance learning;

- the presence of psychological barriers to the transition to the implementation of distance learning.

All these problems, of course, could not but affect the quality of education. The lack of normative regulation of the educational process in the context of the pandemic was one of the prerequisites for increasing the negative consequences. Although the idea of distance learning in modern Russia has been around for years. So, in 1997, the order of the Ministry of education of the Russian Federation n1050 "on conducting an experiment in the field of distance education"was issued. However, this document was never officially published. Then the Order of the Ministry of education of the Russian Federation of 27.06.2000 N 1924 "on experiment in the field of distance education"was issued[7]. This document was published based on the results of an experiment conducted in 1997-1999.

The very purpose of the experiment - the preparation of normative legal documents regulating the use of distance education technologies in the educational process-was also interestingly declared in this Order.

To achieve this objective, it is necessary to analyze the features of changing the education format, among which the following can be distinguished:

1. the need to establish online communication between the teacher and the student without providing a face-to-face meeting

2. shift of the educational process towards an increase in the percentage of independent development of educational material with a given information technology.

These features also determine new functions of the educational process in the context of the pandemic, namely: providing students with educational material using information technologies, online interaction in the learning process, providing students with the opportunity to independently master the material, as well as developing a system for assessing knowledge in the process of distance learning. 
New functions, in turn, transform the educational system itself, changing the objectives and content of training, the means and organizational forms of training, the regulatory and financial and economic base of training. In addition, new principles of the educational process in distance learning are being formed, which can be presented in the form of a table that reflects the formation of new principles, as well as their content:

Table 1. "Principles of the educational process in distance learning"

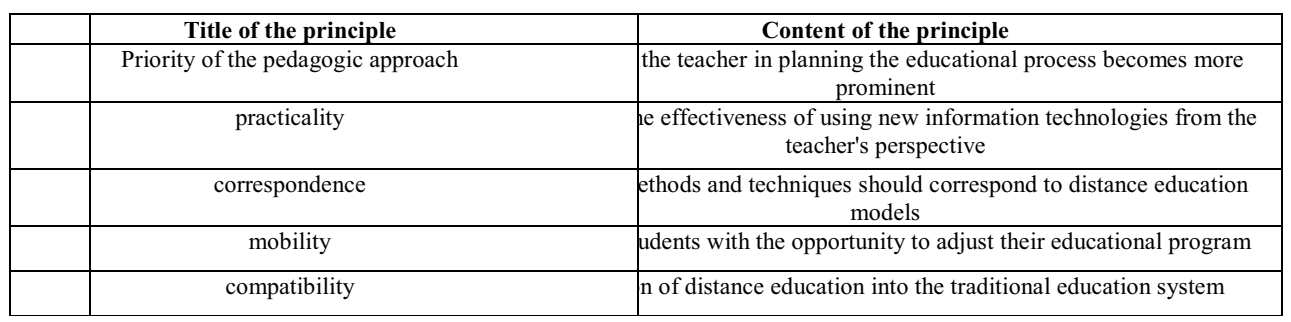

Analysis of the specifics, functions and principles of the educational process in the context of the pandemic allows us to conclude that the workload on the entire educational system is increasing, which in our opinion requires detailed normative regulation of labor relations of employees in the field of education.

In accordance with article 4 of Federal law No. 273-FZ of 29.12.2010 "on education in the Russian Federation": "Relations in the field of education are regulated by the Constitution of the Russian Federation, this Federal law, as well as other Federal laws, other normative legal acts of the Russian Federation, laws and other legal acts of subjects of the Russian Federation containing norms regulating relations in the field of education"[8].

It is important to understand that employees in the field of education, in accordance with the above law, include not only teachers and researchers, but also other employees who perform auxiliary functions-engineering, administrative, production, educationalauxiliary, medical and other employees who perform auxiliary functions.

The labor activity of employees in the field of education is regulated primarily by the Labor code of the Russian Federation, which regulates only general provisions, such as: the right to engage in teaching activities, the specifics of concluding and terminating an employment contract with certain categories of employees, vacation time, grounds for suspension from work.

However, it should be noted that the peculiarities of changing the format of training, new principles of organizing the teacher's work, require completely new competencies from the teacher, i.e. a set of rights, duties, powers, and responsibilities of a particular teacher. In addition, guarantees and compensations should be defined and fixed if the work function changes or the operating conditions change.

All this requires regulatory approval at both the Federal and regional levels.

\section{Discussion}

Studies conducted in this area suggest that there is insufficient legal regulation of labor relations in the field of education in the context of the pandemic. Specialists of the scientific research centre for professional education and qualification systems FIED RAAandGS (Blinov V. I., Sergeev I. S., Esenina E. Yu.) conducted research on the features of organizing online training in the IVE system, which were obtained during the first three months of the fight against the coronovirus pandemic. [9] Several blocks of the organization of distance education in the context of the pandemic were analyzed, including the conditions created for the implementation of distance learning and barriers to the full 
organization of distance learning. When analyzing the conditions for the implementation of distance learning, five directions were evaluated, such as: 1)organizational and legal (availability of local NRA required for transferring to distance learning); 2)organizational and methodological conditions (availability of educational and methodological documentation in an educational institution); 3)organizational and technical; 4)conditions for using remote technologies by students and 5)readiness of the teaching staff to implement online mode [9]. The results were then divided into several groups:

-previously solved (before the pandemic)

-solved in the first week of self-isolation

-partially resolved issues

-mostly unsolved

Analysis of the results allowed us to draw the following conclusions:

- before self-isolation and during the first week of self-isolation, a small part of the tasks was solved (for example, the relevant departments were formed, a platform or other method of organizing training was chosen, etc.)

- the tasks that did not require large resources and time were partially solved (regulations for online training were developed; a list of subjects to be transferred to online training was formed; feedback lines were created with students; group chats were created for teachers to communicate, etc.)

- the main tasks in the organizational and legal direction are considered to be practically unsolved, namely: remuneration of teachers for the development of online courses; remuneration of teachers for the implementation of distance learning; examination of the quality of online courses (ib.).

There is a quite natural question whether the job responsibilities of teachers include the development of online courses. In our opinion, the development of online courses requires special competencies that not all teachers possess. In addition, when hiring teachers, the availability of such competencies is not required by law. This conclusion is confirmed by a study conducted to assess the possibility of involving teachers in the development and use of online courses. Experts came to the following conclusion: "A high-quality online course, from the point of view of teachers, should first of all have a high-quality analyses of educational materials, reliable tools for monitoring learning outcomes, and be organized in accordance with the capabilities and needs of students... the percentage of those who do not want to develop and use online courses was $36 \%$. the main reasons for refusing them are high workload, lack of time, as well as weak organizational mechanisms for involving and stimulating teachers engaged in this type of activity...In general, the widespread introduction of MOOCs in the educational process clearly requires the development of organizational mechanisms to support teachers who develop online courses, including ways to provide them with financial incentives and additional education"[10-15].

Of course all these problematic aspects of labor relations in the educational sector in the context of the pandemic need more detailed legal regulations.

\section{Conclusions}

The coronavirus pandemic has had a serious impact on all aspects of society - economic, political, and social. The educational sector is no exception. New areas, new tools and forms have emerged in the field of education, the most important of which are remote work and online education. New realities require high-quality processing of all educational methods and practices, as well as the creation of a regulatory framework for working in new conditions.

It can be concluded that in the context of the pandemic, there is a shortage of legal regulation in the educational sphere. In particular, the issue of remuneration of teachers in 
the conditions of online education in terms of developing electronic educational resources has not been worked out.

The development of online courses requires that teachers develop new competences, which will undoubtedly require additional training. In this regard, it is necessary to define the rights, duties and powers of the person implementing distance learning at the regulatory level.

Additional training for teachers implies advanced training in distance learning, which is becoming an obvious problem in the context of the pandemic.

Analyzing the research conducted in the field of distance education, it can be stated that material remuneration becomes the most significant incentive for teachers when developing online courses.

Thus, in the context of the pandemic, labor relations in the educational sector need legal regulation, which should include both financial incentives for teachers and tools and methods of additional education.

\section{References}

1. W. Al-Rahami, A. Aldraiweesh, N. Yahaya, Y. Kamin, A. Zeki, Massive Open Online Courses (MOOCs): Data on higher education. Data in Brief, 22, 118-125 (2019) https://doi.org/10.1016/j.dib.2018.11.139

2. R. Zemsky, With a MOOC MOOC Here and a MOOC MOOC There, Here a MOOC, There a MOOC, Everywhere a MOOC MOOC. The Journal of General Education, 63(4), 237-243 (2014) https://doi.org/10.1353/ jge.2014.0029.

3. K. Carey, Everybody Ready for the Big Migration to Online College? Actually, No The New York Times. March 13 (2020) Available at: https://www.nytimes.com/2020/03/13/upshot/coronavirus-online-collegeclassesunprepared.html (Last accessed 16 August 2020)

4. T. Fawns, D. Jones, G. Aitken, Challenging assumptions about "moving online" in response to COVID-19, and some practical advice. MedEdPublish. 9(1), 83 (2020) DOI: 10.15694/mep.2020.000083.1

5. Taylor D., Grant J., Hamdy H., Grant L., et al. Transformation to learning from a distance. MedEdPublish. 2020; 9 (1): 76. DOI: 10.15694/mep.2020.000076.1.

6. K. Douglas, H. Merzdorf, N. Hicks, M. Sarfraz, P. Bermel, Challenges to assessing motivation in MOOC learners: An application of an argument-based approach. Computers \& Education, 150, $103829 \quad$ (2020) https://doi. org/10.1016/j.compedu.2020.103829

7. A. Ortega-Arranz, M. Bote-Lorenzo, J. Asensio-Perez, A. Martinez-Mones, E. GomezSanchez, Y. Dimitriadis, To reward and beyond: Analyzing the effect of reward-based strategies in a MOOC. Computers \& Education, 142, 103639 (2019) https://doi.org/10.1016/j.compedu.2019.103639

8. D. Garrison, H. Kanuka, Blended learning: Uncovering its transformative potential in higher education. The Internet and Higher Education, 7(2), 95-105 (2004) https://doi.org/10.1016/j.iheduc.2004.02.00.00

9. V. I. Blinov, I. S. Sergeev, E. Yu. Esenina, Sudden distance learning: the first month of the emergency (based on the results of Express research and ex-press survey): 2 hours. Professional education and labor market, 2, 6-33 (2020) DOI 10.24411/2307-42642020-10201

10. M. P. Prokhorova, O. I. Vaganova, participation of University teachers in the development of open online courses. Domestic and foreign pedagogics, 1, 5(62), 90- 
103 (2019) B01 10.24411/2224-0772-2019-10033. DOI: 10.26795/2307-1281-2019-74-2

11. O. V. Tikhonova, O. A. Chikhacheva, N. V. Grechushkina, Features of the organization of pedagogical support for students during an online course as part of extracurricular independent work. Perspectives of science and education, 1(43), 57-71 (2020) https://doi.org/10.32744/pse.2020.1.4

12. J. Fang, L. Tang, J. Yang, M. Peng, Social interaction in MOOCs: The mediating effects of immersive experience and psychological needs satisfaction. Telematics and Informatics, 39, 75-91 (2019) https://doi.org/10.1016/j. tele.2019.01.006

13. K. Hew, X. Hu, C. Qiao, Y. Tang, What predicts student satisfaction with MOOCs: A gradient boosting trees supervised machine learning and sentiment analysis approach. Computers \& Education, 145, $103724 \quad$ (2020) https://doi. org/10.1016/j.compedu.2019.103724

14. T. Favale, F. Soro, M. Trevisan, I. Drago, M. Mellia, Campus traffic and e-Learning during COVID-19 pandemic, Computer Networks, 176, 107290 (2020) https://doi.org/10.1016/j.comnet.2020.107290

15. Z. Almarzooq, M. Lopez, A. Kochar, Virtual Learning during the COVID-19 Pandemic: A Disruptive Technology in Graduate Medical Education. Journal of the American College of Cardiology, In Press. (2020) https://doi. org/10.1016/j.jacc.2020.04.015 